\title{
Outcomes of Values and Participation in 'Values-Expressive' Nonprofit Agencies
}

\author{
Granger Macy \\ Ithaca College
}

\begin{abstract}
This paper demonstrates the effect of values and management practices on important employee outcomes including satisfaction, commitment, trust, and self-esteem based on a study of 18 not-for-profit social service agencies. The study focused on the relationship between values and management practices and how this relationship affected the perceived satisfaction and social climate in not-for-profit organizations. Results from the analysis of the survey support an important linkage between values and management practice. This study found support for both direct and contingent effects of values on important organizational outcomes.
\end{abstract}

\section{Introduction}

"Thus, to redesign jobs, reward systems, and human resources management policies that will result in optimum job satisfaction and productivity, managers need to know what employees value" (Karl \& Sutton, 1998, p. 515).

This statement represents the essential thrust of this paper. In addition to Karl and Sutton (1998) others including Jeavons (1992), Frumkin (2002), and Mason (1996) have supported this assertion in discussions of the not-for-profit sector. Jeavons (1992) contends that nonprofit organizations are values-expressive and thus the study of values in the nonprofit sector is an especially important investigation. Frumkin (2002) elaborates on this idea and states that "(b)y committing to broad causes that are close to the heart or by giving to an effort that speaks directly to the needs of the community, nonprofit and voluntary action answers a powerful expressive urge" (p. 23). Mason (1996) goes on to suggest why the proper support of personnel may be particularly important in the expressive nonprofit sector:

"People work with nonprofits to fulfill their expressive hunger for relatedness, rootedness, affection, approval, admittance, security, esteem, affiliation, and other expressive activities. ... (A) group enables and lifts up its members to accomplish more than they would alone, it buoys them up and supports them expressively. Individuals' efforts and emotions are not constant.... A group can mediate with and support its members during low periods, making these periods shorter and shallower than they would otherwise be" (Mason,1996, p. 224)

However, the impact of personal values and employee support on employee outcomes is largely untested. Karl and Sutton (1998) showed that public sector employees do have different values from private sector employees, but did not evaluate the core question of whether values do, in fact, influence work-related attitudes and behaviors. The present research is a cross-sectional study of small social service agencies. Specifically, this research examines the relationship between values, participative 
practices and important employee outcomes including job satisfaction, peer trust, and self-esteem. Participative practices are a focus since many studies have reported on the linkage between involvement and work-related attitudes and behaviors (e.g. Kim, 2002, Tesluk, Vance \& Mathieu, 1999). This is an important issue since an understanding of the nature of the linkage between values, participative practices and important work outcomes can provide important guidance in the selection of appropriate management practices.

\section{Assessing Values and Management Practices}

Although values are discussed with increasing frequency, values are often conceptualized loosely and the discussion of values tends to be prescriptive. Thus it is important to begin by carefully identifying and defining specific values relevant to management practice. A value (or normative belief) can be defined as "an enduring belief that a specific mode of conduct or end-state of existence is personally or socially preferable to an opposite or converse mode of conduct or end-state of existence" (Rokeach, 1973: 5). Values can be understood as an individual's world view, one based on underlying principles of social justice and the importance of the individual in society. Values lie at the core of personality influencing individual choices and actions (Posner \& Schmidt, 1996) and when they are socially derived, values can also act as norms which influence behavior in groups (Wiener, 1982).

Values are proposed to have important effects on organizational and employee functioning. Collins and Porras (1996, p. 73-76) noted that the highest performing forprofit companies had strong core values unlike lower performing companies. And the consideration of values may be especially important for the nonprofit organization (Armstrong, 1992; Jeavons, 1992; Mason, 1996). In a study of a voluntary service organization, Rousseau (2000) found that normative beliefs, as a measure of shared cultural values impacted performance outcomes. Jeavons (1992) further suggests that values of organizational integrity, service to the public good, and concern for participant welfare are central concerns in many nonprofit organizations.

Values should not be considered in isolation, but should be viewed as an integrated system. However, values research has largely failed to consider the overall structure of values (Connor \& Becker, 2003). Although there are many different dimensions of values that have been offered in the literature, a common system of values appears particularly relevant to the concerns of organizations. Bucholz (1977), Wiener (1988), and O'Toole (1993) have each discussed related conceptions of values which could be described as control vs. choice, and individualism vs. collectivism. Each pair of these values represents different dimensions which can only be balanced. Each value represents an ideal, an extreme that would be unlikely to lead to a productive organization.

The values of control vs. choice have been called functional (Wiener, 1988). Functional values concern the mode of conduct of organizational members and the degree to which divergent behaviors and performance are tolerated. Concerned with efficiency and order, control values place emphasis on the structuring of job behaviors into common, predefined categories. Choice values, on the other hand, emphasize work 
enrichment, the quality of work life, individual expression, and individual satisfaction. Managers with values identified as control may be unwilling to accommodate workforce differences. Their emphasis would be on control and commonality among different aspects of the workforce. A choice value, however, would likely lead to greater diversity and an appreciation of the different contributions that each member might bring to the workplace.

The other dimension, individualism vs. collectivism has been used in many forms including, most typically, cross cultural research. The concern here is different, however, in that it focuses on assumptions about the nature of work and the status of individuals. These values have been identified as elitist (Wiener, 1988). Elitist values focus on whether work outcomes result from individual effort or from the contribution of a larger group. With an individual emphasis, value is placed on one's position, on differentiation between workers, and on self-reliance. Collectivism, on the other hand, values group support and rewards that would accrue to all equally. Under collectivism, one would be less concerned with seeking the superstar and more concerned with building a cohesive work unit that respects legitimate differences between workers. It would place less importance on performance differences in individuals, but would value cooperation and team work.

In addition, humanistic or self-actualizing (Rousseau, 1990) values may be especially important in a nonprofit environment where employees may trade a reduced salary for more personal forms of compensation. Humanistic values focus on the nature of the work as satisfying and as a means of self-expression. These values represent a positive orientation to work. I contend that such values alone can impact on one's perception of work and lead to preferred worker outcomes. Rousseau (2000), for example, found that satisfaction-oriented beliefs were positively correlated with positive perceptions of the job such as role clarity and job satisfaction.

Hypothesis 1. Humanistic values are related to successful employee outcomes.

Management practices have been frequently based either explicitly or implicitly on the control of poorly motivated workers. Since the era of Henry Ford and Frederick Taylor, mainstream organizational and behavioral theories have considered an organization as a machine to be controlled, and employees to be a part of the machine (Morgan, 1986). The driving force in designing organizations under this view becomes the rational control of production focusing on such organizational characteristics as centralization, coordination, and job specialization.

As organizations have begun to reduce their reliance on hierarchical controls and bureaucratic structures, many organizations have been undergoing redesign efforts including flat organization structures and increased employee participation. Clegg (1990) terms this new trend the 'post-modern organization' which he identified with democracy, market alignment, empowerment, trust, and collectivity (p203). It is based in the natural systems model which "recognizes the forces and energies in organizations that flow from the natural tendencies of individuals and groups to meet their needs for social relations, influence, and psychological growth by seeking autonomy to exercise their own purposefulness" (McKelvey \& Kilmann, 1975, p.26). 
One might anticipate an increased sense of esteem and better social relationships or trust to result in such an environment.

Locke (1976) suggested that values can impact job satisfaction if the job is perceived as fulfilling a workers important job values. Studies in the nonprofit sector (Kim, 2002; Tesluk et al., 1999) have also found that participation can lead to positive work attitudes and behaviors leading to the following hypothesis.

Hypothesis 2. Participative practices are related to successful employee outcomes.

Schein (1992) suggests that values and beliefs of both an organization's employees and leaders are important management considerations. I contend that values are important considerations because they can impact the effectiveness of certain management practices. Shared values and beliefs are cultural elements of an organization that can influence both perceptions and behaviors (Fiol, 1991) suggesting that specific values and beliefs within an organization may impact the acceptance or rejection of certain management practices. Leana, Ahlbrandt and Murrell (1992) noted that while involvement practices may affect attitudes and perceptions, proper implementation may be necessary for such programs to generate the desired effects. The Leana study found that frustration and not satisfaction was higher for employees in a participative decision making process. Yeung et al. (1991) found significant relationships between emphasis on certain human resource (HR) practices and cultures using the Quinn competing values model. Considering the possible linkages between values and practices, I can propose the following.

Hypothesis 3. Individual values moderate the achievement of successful employee outcomes using participative practices.

\section{Methodology}

The data for this study included 184 participants in 18 social service, not-for-profit agencies. Based on the Jeavons (1992) and Beres and Wilson (1997), non profit organizations were considered the best candidates for an exploratory study on the importance of values. With a decreased emphasis on monetary rewards, such organizations depend on personal values for motivation. Many organizational members have also been educated and instilled with a set of professional values and ethics that would likely be conducive to more participative management practices. The participants in this study were largely female, educated, social service professionals. The study population was $73 \%$ female, and had an average age of 38.8 . In addition, $56 \%$ had a four year college degree or greater, $74 \%$ had one year of tenure or more, $67 \%$ were employed full time and $17 \%$ of respondents were volunteers. Participants in the study were sought through monthly director's meetings of the United Way or through other local non profit associations. At the meetings, directors were briefed on the purpose and requirements of the study, and possible advantages which could accrue from their participation in the study. Because of the method of solicitation, it is impossible to get a precise estimate of the number of agencies that were reached. It is estimated, however, that at least 50 percent of the possible agencies in the region participated in the study. 
The research process included two major components: a survey of agency employees and/or volunteers, and interviews with agency directors. All data were collected on site. A convenient time was scheduled with each agency so that all needed data could be collected at one time. All data were collected by the primary researcher. Each visit began with a taped interview of the director. After the interview, all employees, including the director were convened in one place to complete the survey questionnaire. The time of the survey was selected so as to maximize the number of employees who could participate. In most agencies, the meetings coincided with the agencies' monthly staff meetings.

The surveys were administered to the employees under a pledge to keep all individual results strictly confidential. All employees were able to complete the survey in under half an hour. Employees who were not present at the data gathering session were given a questionnaire when they returned to work, and were given a return mail envelope to assure confidentiality. In addition to basic demographic information, the survey collected specific data on company practices, employee values, and employee affective responses. The measures of practices included constructs to measure progressive management practices, and psychological participation (Vroom, V.H. 1960). A scale for progressive management practices was constructed from typologies developed by Jackson et al. (1989), and Schuler \& Jackson (1987). Scales for this measure included employee recognition, employee input and performance management practices. An additional scale for information access was developed from Lawler et al. (1992).

The values component was measured using the Beliefs About Work scale developed by Bucholz (1977) and a scale to measure values relating to the management of organizations. There was no existing scale for this last measure. Prior to analysis all independent variables were factor analyzed and the scales were trimmed to eliminate items that loaded poorly. Progressive management practices and psychological participation failed to create separate factors. Progressive management practices were thus dropped since psychological participation created a more reliable scale. After the scales were trimmed the remaining items representing the independent variables were factor analyzed together. The results of this analysis, description of the final items, and the reliability coefficients for each scale are presented in Table 1. 
Table 1.

Results of Factor Analysis of the Independent Variables

\begin{tabular}{|c|c|c|c|c|c|c|}
\hline Factors and Items & 1 & 2 & 3 & 4 & 5 & 6 \\
\hline \multicolumn{7}{|l|}{ Humanist Values ( $\alpha=.869)$} \\
\hline \multirow{3}{*}{$\begin{array}{l}\text { II. }- \text { - Work can be made satisfying } \\
\text { II. } 19 \text { - Work can be a means for self-expression } \\
\text { II.24 - Work can be organized to allow for } \\
\text { human fulfillment }\end{array}$} & 0.292 & 0.779 & 0.206 & -0.012 & 0.092 & 0.139 \\
\hline & 0.269 & 0.831 & 0.167 & 0.083 & 0.104 & 0.149 \\
\hline & 0.115 & 0.840 & 0.165 & 0.112 & 0.086 & 0.162 \\
\hline \multicolumn{7}{|l|}{ Collective Values ( $\alpha=.828$ ) } \\
\hline $\begin{array}{l}\text { II.9 - One's contribution to the group is the most } \\
\text { important thing about one's work }\end{array}$ & 0.058 & 0.262 & 0.814 & 0.182 & 0.077 & 0.041 \\
\hline $\begin{array}{l}\text { II.10 - One should take an active part in all } \\
\text { group affairs }\end{array}$ & 0.062 & 0.097 & 0.848 & 0.121 & 0.094 & 0.141 \\
\hline $\begin{array}{l}\text { II.31 - The group is the most important entity in } \\
\text { any organization }\end{array}$ & 0.127 & 0.138 & 0.772 & 0.107 & 0.120 & 0.146 \\
\hline \multicolumn{7}{|l|}{ Individual $(\alpha=.701)$} \\
\hline $\begin{array}{l}\text { II.4 - One must avoid dependence on other } \\
\text { people wherever possible }\end{array}$ & 0.043 & 0.207 & 0.051 & 0.162 & 0.727 & -0.088 \\
\hline $\begin{array}{l}\text { II.7 - Only those who depend on themselves get } \\
\text { ahead in life }\end{array}$ & -0.078 & 0.039 & 0.151 & 0.071 & 0.792 & 0.230 \\
\hline $\begin{array}{l}\text { II.30 - One should live one's own life } \\
\text { independent of others as much as } \\
\text { possible }\end{array}$ & 0.069 & 0.034 & 0.069 & 0.095 & 0.783 & 0.106 \\
\hline \multicolumn{7}{|l|}{ Work Control Values $(\alpha=.735)$} \\
\hline $\begin{array}{l}\text { IIA. } 5 \text { - Things are done better when employees } \\
\text { are told what to do }\end{array}$ & 0.029 & 0.040 & 0.106 & 0.808 & 0.128 & 0.017 \\
\hline $\begin{array}{l}\text { IIA.8 - Things would work better if policies are } \\
\text { closely followed }\end{array}$ & 0.139 & 0.175 & 0.285 & 0.683 & 0.106 & 0.011 \\
\hline $\begin{array}{l}\text { IIA.9 - Agencies should continuously monitor an } \\
\text { individual's decisions and actions to be } \\
\text { sure that things are done right }\end{array}$ & 0.140 & -0.017 & 0.048 & 0.824 & 0.101 & 0.095 \\
\hline \multicolumn{7}{|l|}{ Worker Choice Values ( $\alpha=.641$ ) } \\
\hline $\begin{array}{l}\text { IIA.3 - Expectations for the agency are best met } \\
\text { by letting employees figure out what } \\
\text { needs to be done }\end{array}$ & -0.081 & 0.090 & 0.023 & 0.137 & 0.150 & 0.772 \\
\hline $\begin{array}{l}\text { IIA.10 - Work gets done better if a supervisor } \\
\text { tells an employee what needs to be } \\
\text { done, and then lets the employee } \\
\text { choose how to do it }\end{array}$ & 0.268 & 0.170 & 0.264 & 0.109 & 0.001 & 0.611 \\
\hline $\begin{array}{l}\text { IIA.11 - Agencies work better when employees } \\
\text { are allowed to assume responsibility for } \\
\text { setting their own performance goals }\end{array}$ & 0.085 & 0.145 & 0.106 & -0.091 & 0.066 & 0.762 \\
\hline \multicolumn{7}{|l|}{ Psychological Participation ( $\alpha=.870)$} \\
\hline $\begin{array}{l}\text { III.5 - I have a great deal of influence on what } \\
\text { goes on in my job } \\
\text { III. } 10 \text { - I can influence the decisions of my }\end{array}$ & 0.773 & 0.151 & 0.134 & 0.075 & -0.086 & 0.109 \\
\hline $\begin{array}{l}\text { immediate superior regarding things } \\
\text { about which I am concerned }\end{array}$ & 0.812 & 0.186 & -0.085 & 0.045 & -0.016 & 0.191 \\
\hline $\begin{array}{l}\text { III.15 - My supv. always asks my opinion when } \\
\text { a problem comes up that involves my job }\end{array}$ & 0.845 & 0.108 & 0.129 & 0.097 & 0.088 & -0.020 \\
\hline $\begin{array}{l}\text { III.20 - If I have a suggestion for improving the } \\
\text { job or changing the work in some way, it } \\
\text { is easy for me to get my ideas across to } \\
\text { my superior }\end{array}$ & 0.851 & 0.174 & 0.100 & 0.121 & 0.075 & 0.037 \\
\hline
\end{tabular}


The dependent variables of the study focused on employee affective responses. These variables included measures of overall job satisfaction (Seashore et al. 1982), social reward satisfaction (Seashore et al. 1982), interpersonal trust at work (Cook \& Wall, 1980), organizational commitment (London \& Howat, 1978), and organization based self esteem. The scale for organization based self esteem was based on Pierce et al. (1989), but the items included in the survey focused on feelings of employee validation and recognition.

Prior to analysis all dependent variables were factor analyzed and the scales were trimmed to eliminate items that loaded poorly. In this stage it was found that several items did not load as anticipated. Social reward satisfaction, organization commitment and trust in management were eliminated since organizationally based self esteem was sufficient to adequately represent the construct based on the results of the factor analysis. After those items were deleted and the other scales trimmed appropriately all remaining items representing the dependent variables were factor analyzed together. The results of this analysis, description of the final items, and the reliability coefficients for each scale are presented in Table 2.

Table 2

Results of Factor Analysis of the Dependent Variables

\begin{tabular}{llll}
\hline Factors and Items & 1 & 2 & 3 \\
\hline Job Satisfaction ( $\alpha=.816)$ & & & \\
VI.I - I would leave this agency if offered the same job with & -0.072 & -0.062 & $\mathbf{0 . 8 4 7}$ \\
$\quad$ another agency. (R) & -0.148 & 0.000 & $\mathbf{0 . 8 2 7}$ \\
VI.7 - In general, I don't like my job. (R) & & \\
Peer Trust ( $\alpha=.911)$ & & & \\
V.8 - Most of my coworkers can be relied upon to do as they say & 0.375 & $\mathbf{0 . 7 8 0}$ & -0.134 \\
$\quad$ they will do & 0.386 & $\mathbf{0 . 8 2 3}$ & -0.095 \\
V.9 - I have full confidence in the skills of my coworkers & 0.284 & $\mathbf{0 . 8 5 7}$ & 0.070 \\
V.10 - Most of my fellow workers would get on with the job even & & & \\
$\quad$ if supervisors were not around & 0.283 & $\mathbf{0 . 8 2 7}$ & -0.017 \\
V.11 - I can rely on other workers not to make my job more & & & \\
$\quad$ difficult by careless work & & & \\
Organizational Self Esteem ( $\alpha=.946)$ & $\mathbf{0 . 8 3 2}$ & 0.228 & -0.131 \\
V.13 - My knowledge and experience are valued in this agency. & $\mathbf{0 . 7 6 2}$ & 0.290 & -0.026 \\
V.14 - I can make a difference here & $\mathbf{0 . 8 5 8}$ & 0.313 & 0.049 \\
V.15 - People here have faith in me & $\mathbf{0 . 8 1 8}$ & 0.348 & -0.221 \\
V.16 - My contributions to the agency are appreciated & $\mathbf{0 . 8 3 4}$ & 0.347 & -0.138 \\
V.17 - I am taken seriously around here & $\mathbf{0 . 8 4 3}$ & 0.328 & -0.199 \\
V.18 - I feel like a valued and unique person around here &
\end{tabular}

\section{Results}

Table 3 on the next page shows the means, standard deviations, and correlation matrix for the final variables. 


\begin{tabular}{|c|c|c|c|c|c|c|c|c|c|c|c|c|c|c|c|c|c|}
\hline \multicolumn{18}{|c|}{$\begin{array}{c}\text { Table } 3 \\
\text { Means, Standard Deviations, and Correlations for All Variables }\end{array}$} \\
\hline Variables & Mean & s.d. & 1 & 2 & 3 & 4 & 5 & 6 & 7 & 8 & 9 & 10 & 11 & 12 & 13 & 14 & 15 \\
\hline \multicolumn{18}{|l|}{ Values: } \\
\hline 1. Humanist & 5.985 & .752 & & & & & & & & & & & & & & & \\
\hline 2. Collective & 4.674 & 1.084 & .047 & & & & & & & & & & & & & & \\
\hline 3. Individual & 3.556 & 1.256 & -.076 & .079 & & & & & & & & & & & & & \\
\hline 4. Control & 4.136 & 1.067 & -.117 & $.199^{* *}$ & $.185^{*}$ & & & & & & & & & & & & \\
\hline 5. Choice & 4.808 & .914 & .034 & .102 & .064 & -.087 & & & & & & & & & & & \\
\hline \multicolumn{18}{|l|}{ Management Practice: } \\
\hline $\begin{array}{l}\text { 6. Psychological } \\
\text { Participation }\end{array}$ & 5.201 & 1.268 & $.260^{* *}$ & .004 & .072 & .054 & .037 & & & & & & & & & & \\
\hline \multicolumn{18}{|l|}{ Affective Outcomes: } \\
\hline 7. Social Satisfaction & 5.798 & 1.086 & $.241^{* *}$ & .009 & -.067 & -.043 & .018 & $.501^{* *}$ & & & & & & & & & \\
\hline 8. Job Satisfaction & 4.547 & 1.284 & $.284^{* *}$ & .074 & -.052 & -.082 & -.029 & $.494^{* *}$ & $.548^{* *}$ & & & & & & & & \\
\hline 9. Peer Trust & 5.638 & .985 & $.178^{*}$ & .122 & $.155^{*}$ & -.064 & .072 & $.242^{* *}$ & $.600^{* *}$ & $.441^{* *}$ & & & & & & & \\
\hline 10.Org Self Esteem & 5.514 & 1.121 & $.266^{\star *}$ & .076 & $.191^{*}$ & .040 & .016 & $.586^{* *}$ & $.641^{* *}$ & $.544^{\star *}$ & $.535^{* *}$ & & & & & & \\
\hline \multicolumn{18}{|l|}{ Controls: } \\
\hline 11.Tenure & 3.658 & 3.224 & -.078 & .139 & -.118 & .123 & .050 & .087 & .097 & .085 & .085 & $.150^{*}$ & & & & & \\
\hline 12.Paid Status & .835 & .372 & $.170^{*}$ & -.084 & .004 & -.045 & .069 & -.074 & $-.147^{*}$ & $-.20^{\star \star}$ & -.125 & -.026 & -.061 & & & & \\
\hline 13.Hours/Week & 33.659 & 11.301 & $.218^{\star \star}$ & -.074 & .024 & $.157^{*}$ & $.148^{*}$ & -.033 & -.073 & -.144 & $-.164^{*}$ & -.064 & -.013 & $.314^{* *}$ & & & \\
\hline 14.Education Level & 3.099 & 1.577 & $.322^{* *}$ & $-.22^{* *}$ & $.152^{*}$ & $-.27^{* *}$ & $.165^{*}$ & .066 & .068 & -.092 & .002 & .141 & -.081 & $.188^{\star}$ & $.341^{* *}$ & & \\
\hline 15.Female & .729 & .446 & .106 & -.001 & .075 & $.162^{-}$ & .069 & -.070 & -.109 & .036 & .046 & -.052 & -.037 & $.197^{\star \star}$ & .009 & $.177^{*}$ & \\
\hline 16.Age & 38.83 & 12.463 & -.090 & -.032 & $.187^{-}$ & $.162^{*}$ & -.097 & -.028 & $.199^{* *}$ & .120 & $.221^{* *}$ & .081 & $.268^{* *}$ & -.126 & -.144 & -.099 & $.113^{-}$ \\
\hline $\begin{aligned} *{ }^{*} p & <.10 \\
. * * & <.05\end{aligned}$ & & & & & & & & & & & & & & & & & \\
\hline
\end{tabular}


To test the specific hypotheses, moderated regression analysis was used to isolate the main effects of values on outcomes and to independently assess how each value moderated the relationship between practices and outcomes. Early in the analysis it became clear that volunteers were consistently more positive in their assessments and appeared to react to the issues of the studies differently than the paid participants. As a result, the regression analyses included the paid participants only $(n=144)$ since there was inadequate statistical power to separately analyze the volunteers. It should also be noted that all data in the study at this point consists of individual perceptual data suggesting that the aggregation of data across companies is appropriate. Indeed, control for variances induced by organizational factors would likely strengthen any results that might be found.

The overall procedure for each dependent variable was the same. In step one, control variables including tenure, work hours, education level, gender and age were added as a set. These variables were added to control for any demographic variations that may have impacted on the participants' response. In step two, the set of values (individual, collective, control, choice, humanist) were added to control for any direct effects that values may have had on organizational outcomes. In the third step, practices which were included as psychological participation were added. In the fourth step, the cross products of practices and values were entered as a set. Entering the interaction terms simultaneously controlled for possible multicollinearity among the variables. Significant effects at this stage would indicate that values moderate the relationship between practices and organizational outcomes. The individual interaction terms can then be used to test the specific hypotheses if the terms accounted for significant residual variance. Tables 4,5 and 6 show the results of the moderated hierarchical regression analyses.

Table 4

Results of Regression Analysis for Job Satisfaction

\begin{tabular}{lrrrr}
\hline Variable & Step 1 & Step 2 & Step 3 & Step 4 \\
\hline Control & & & & \\
$\quad$ Tenure & .054 & 0.92 & 0.47 & 0.35 \\
Hours & -.097 & -.079 & -.055 & -.052 \\
Education Level & .029 & $-.157^{*}$ & $-.157^{*}$ & $-.155^{*}$ \\
Female & .062 & -.016 & .031 & .026 \\
$\quad$ Age & .108 & .104 & $.145^{* *}$ & $.147^{*}$ \\
Values & & & & \\
$\quad$ Individual & & .054 & .083 & -.237 \\
Collective & & .046 & .068 & -.267 \\
Control & & -.102 & $-.153^{* *}$ & .050 \\
Choice & & -.032 & -.063 & -.318 \\
$\quad$ Humanist & & $.470^{* *}$ & $.312^{* *}$ & .220 \\
Psychological Participation & & & $.429^{* *}$ & -.457 \\
Psychological Participation interactions with & & & & \\
$\quad$ Individual & & & & .378 \\
Collective & & & & .494 \\
Control & & & & -.259 \\
$\quad$ Choice & & & & .419 \\
Humanist & & & & .202 \\
${ }^{*} p<.10,{ }^{* *} p<.05$ & & & &
\end{tabular}




\begin{tabular}{lrrrr}
\hline Variable & Step 1 & Step 2 & Step 3 & Step 4 \\
\hline Control & & & & \\
$\quad$ Tenure & .018 & .023 & .004 & -.001 \\
Hours & $-.163^{*}$ & $-.179^{* *}$ & $-.169^{*}$ & $-.152^{*}$ \\
Education Level & .082 & -.021 & -.021 & .005 \\
Female & .064 & -.001 & .019 & .000 \\
$\quad$ Age & $.171^{* *}$ & $.178^{* *}$ & $.196^{* *}$ & $.188^{* *}$ \\
Values & & & & \\
$\quad$ Individual & & -.062 & -.050 & -.104 \\
Collective & .116 & .126 & .222 \\
Control & & -.111 & -.132 & -.334 \\
Choice & & .114 & .101 & $-.833^{* *}$ \\
$\quad$ Humanist & & $.170^{*}$ & .103 & -.400 \\
Psychological Participation & & & $.181^{* *}$ & $-2.187^{*}$ \\
Psychological Participation interactions with & & & & \\
$\quad$ Individual & & & & .024 \\
Collective & & & & -.152 \\
Control & & & & .361 \\
Choice & & & & $1.599^{* *}$ \\
Humanist & & & & 1.253 \\
${ }^{*} p<.10,{ }^{* *} p<.05$ & & & &
\end{tabular}


Table 6

Results of Regression Analysis for Organizational Self Esteem

\begin{tabular}{lrrrr}
\hline Variable & Step 1 & Step 2 & Step 3 & Step 4 \\
\hline Control & & & & \\
$\quad$ Tenure & .117 & .121 & .067 & .045 \\
Hours & $-.156^{*}$ & -.119 & -.091 & -.079 \\
Education Level & $.230^{* *}$ & .157 & $.158^{*}$ & $.163^{* *}$ \\
Female & -.036 & -.041 & .015 & -.006 \\
$\quad$ Age & .080 & .048 & .098 & .114 \\
Values & & & & \\
$\quad$ Individual & & -.119 & -.085 & $-.542^{* *}$ \\
Collective & & .080 & .107 & -.220 \\
Control & & .089 & .028 & .320 \\
Choice & & -.054 & -.091 & -.533 \\
Humanist & & $.295^{* *}$ & .104 & -.371 \\
Psychological Participation & & & $.517^{* *}$ & -1.433 \\
Psychological Participation interactions with & & & & \\
$\quad$ Individual & & & & $.536^{*}$ \\
Collective & & & & .477 \\
Control & & & & -.386 \\
Choice & & & .697 \\
Humanist & & & 1.257 \\
${ }^{*} p<.10,{ }^{* *} p<.05$ & & &
\end{tabular}

The main effects of the regression analyses will be discussed first. With the demographic variables entered as control, values as a set were significantly related to the dependent variables of job satisfaction $(\Delta \mathrm{r} 2=.21, \mathrm{~F}=7.340, \mathrm{p}<.001)$, peer trust $(\Delta \mathrm{r} 2=.08, \mathrm{~F}=2.312, \mathrm{p}<.05)$, and organizational self esteem $(\Delta \mathrm{r} 2=.10, \mathrm{~F}=3.375, \mathrm{p}<.01)$. Specifically, the humanist value orientation had a significant main effect on job satisfaction $(b=.470, p<.001)$, on peer trust $(b=.170, p<.10)$, and on organizational self-esteem $(b=.295, p<.01)$. Overall, this provides support for the hypothesis that the humanist values orientation will affect employee outcomes.

With both demographic variables and values in the regression, psychological participation was found to be related to job satisfaction $(\Delta \mathrm{r} 2=.15, \mathrm{~F}=33.451, \mathrm{p}<.001)$, peer trust $(\Delta \mathrm{r} 2=.03, \mathrm{~F}=$ $4.327, p<.05)$, and organizational self esteem $(\Delta r 2=.22, F=49.677, p<.001)$. These results show support for the relationship between management practice and all measured organizational outcomes.

The moderating effects of the regression analyses were similarly supportive. Beyond the direct effects of values and practices, there was support for contingency relationships between values and practices. As a set the interaction terms accounted for marginally significant incremental variance in peer trust $(\Delta r 2=.05, F=1.747, p<.10)$ and organizational self esteem $(\Delta r 2=.04, F=1.903, p$ $<.10)$ but not in job satisfaction. Specifically, the choice value orientation significantly moderated the effect of participation on peer trust $(b=1.599, p<.05)$ and the individual value orientation significantly moderated the effect of participation on organizational self esteem $(b=.536, p<.10)$. 


\section{Discussion}

The analysis provides support for all the hypotheses demonstrating the linkages between practices, values, and organizational outcomes. As stated in hypothesis 1, the value orientations emphasizing employee worth was related to successful organizational outcomes. Specifically, the humanist value orientation was significantly related to all outcome measures. Individuals with a humanist value orientation basically believed that people should be entitled to fulfilling work. This belief was related to higher scores on all measures including job satisfaction, organizational esteem, and peer trust.

Practices, too, were related to the outcome variables. As stated in hypothesis 2 , participative practices were positively related to all outcome variables. Finally, in the case of peer trust and organizational self esteem I found support for the third hypothesis. The choice value orientation moderated the power of psychological participation in predicting peer trust. The individual value orientation moderated the power of psychological participation in predicting organizational self esteem.

A range of related practice measures including employee needs/recognition, employee input, information sharing and performance management were collected and analyzed but all proved to be highly related to the measure of psychological participation. Thus in this study management practices are represented only in terms of psychological participation. However, this is clearly a very strong conceptual scale being related to other measures of supportive practices.

Psychological participation also demonstrated very strong computational indices for both validity and reliability.

It is also worth noting that the dependent measures clearly captured different aspects of organizational outcomes. The highly discrete factor loadings were just one indication of this. An examination of the control variables showed the inherent underlying dimensionality of these measures. For example, education level was significantly related to decreased job satisfaction. Educational level would likely sensitize employees to the larger possibilities of their work, and deficiencies in the current situation become more salient for these individuals. However, education level was positively related to organizational self esteem. The education level probably offered participants an improved status and hence self esteem about their position in the organization. Lastly, educational level was not related to peer trust. Interestingly, a decline in peer trust was significantly related to increased hours worked per week. Perhaps the old saw that familiarity breeds contempt holds true in the workplace as well.

Considering the positive indications reported for the measures of psychological participation and outcomes, the strong results for psychological participation must be given considerable weight. Psychological participation impacted positively on several different dimensions of employee affective response. This brings us to the interaction effects. Two effects proved significant. The effect of psychological participation was impacted by choice in predicting peer trust, and by the individual value orientation in predicting organizational self esteem. These effects are especially noteworthy considering the modest sample size and the number of variables in the analysis at this point.

Psychological participation was more important in the presence of a strong choice value orientation in predicting peer trust. This suggests that a belief in the value of employees determining their work 
priorities improves the formation of trust when they are actually given the ability to participate in organizational decisions. Perhaps in this environment participants were more fully freed to develop personal work relationships and respond to their peers when needs arose without undue concern for restrictive policies.

Psychological participation was also more important in the presence of individual values in predicting organizational self esteem. In fact, the positive main effect between participation and organizational self esteem became negative in the presence of the interaction, as did the contribution of individual value scores. This suggests that the opportunity to express oneself through participation is particularly critical towards generating a sense of personal esteem at work. Esteem especially is an individually based concept. Thus esteem is fully supported in both the belief system and by the ability to express one's individuality through participative processes.

\section{Implications and Limitations}

This study has provided preliminary evidence to suggest that practices mirroring workplace values may be more effective. If progressive management practices depart from accepted values and beliefs, an organization may be less successful in utilizing these techniques because of employee values. Practices consistent with commonly held values may be more likely to produce positive outcomes.

It is worth noting that values also change over time. Such changes could very likely affect attitudes towards new, as well as, existing practices. A broad survey of the membership of the American Management Association showed rapid growth in the importance of cooperative values (Posner \& Schmidt, 1992). Posner and Schmidt reported that in 1981, cooperative values were rated important to the quality of work life by only $19 \%$ of the respondents compared to $40 \%$ in 1991 . Individual values, on the other hand, declined from $61 \%$ to $46 \%$ in the same ten year period. Just as values of individualism and collectivism may change, values concerning control and choice may change also. Such changes could bring an increased receptiveness either to team based or to participative practices.

If the success of management practices may depend on the values and beliefs in the organization, then value differences or value changes become an important management issue for study. As values vary over time or across different organizations, effective management may require a continual effort to match the characteristics of practices and values. And if nonprofits are valuesexpressive, as Jeavons (1992) contends, then the management of nonprofit organizations must be especially sensitive to values.

The participation variable in this study had uniformly strong and significant results across all employee outcomes in this study. However, reviews of the literature on the effect of participation on employee outcomes have generally concluded the effect to be small (e.g. Cotton et al., 1988, Wagner, 1994). Several studies have searched for alternative explanations to explain the small effect size noted in the studies. Leana et al. (1992) considered implementation in an attempt to explain the sometimes weak results. A meta-analysis by Wagner et al. (1997) found that the nature of the participation construct had a small effect on the results. 
This study now suggests that a mismatch with values may also explain some of the weak findings. As noted earlier, Collins and Porras (1994) have suggested that strong core values are an attribute of the best performing for profit companies. In addition, their study of successful visionary companies also suggested that there was a linkage between values and administrative mechanisms. Similarly, the linkage of values and practices in this study also appears to lead to positive employee outcomes. Certainly, the strength of these findings gives credence the Jeavons (1992) claim about the values-expressiveness of nonprofits. The non profit social service organizations in this study may be an ideal case for showing the importance of values. However, Collins and Porras (1994) findings suggest that strong values can be developed elsewhere, and when these values are linked to appropriate practices beneficial outcomes could accrue for a broad range of organizations.

A broader study could help clarify the generality of these findings to the for-profit sector. As noted earlier, the nonprofit sample was used since it was believed that the importance of values would be more readily observable in the non profit sector than in the for profit sector. Future work should now focus on the for profit sector to expand our understanding of the boundaries of the linkage between values, practices, and outcomes.

Psychological participation, as a practice, appears to be an important construct. Unfortunately, in the present study I was limited to understanding the concept of progressive management practices in a fairly broad sense. Given the strong results for psychological participation, it would also be useful in the future to ascertain if there are dimensions of participation or other progressive management practices which are more important and perhaps more dependent on an individual's value orientation. Future studies should also incorporate a consideration of more conventional management practices built on control to determine how values orientations might impact their effectiveness. With the growing attention and rhetoric given to values and participation in the workplace, extending these results could provide very useful guidance to future managers.

\section{References}

Armstrong, M. (1992). A Charitable Approach to Personnel. Personnel Management, 24(12): 28-32

Beres, Z. \& Wilson, G. (1997). Essential Emotions: The Place of Passion in a Feminist Network. Nonprofit Management \& Leadership, 8(2): 171-182

Bucholz, R.A. (1977). The Belief Structure of Managers Relative to Work Concepts Measured By a Factor Analytic Model. Personnel Psychology, 30: 567-587

Clegg, S.R. (1990). Modern Organizations: Organization Studies in the Postmodern World. London: Sage

Collins, J.C. and Porras, J.I. (1994). Built To Last: Successful Habits Of Visionary Companies. N.Y.: Harper Business

Connor, P.E., and Becker, B.W. (2003). Personal Value Systems and Decision-Making Styles of Public Managers. Public Personnel Management, 32(1): 155-180 
Cook, J. \& Wall, T.D. (1980). New Work Attitude Measures Of Trust, Organizational Commitment and Personal Need Fulfillment. Journal of Occupational Psychology, 53: 39-52

Cotton, J.L., Vollrath, D.A., Froggatt, K.L., Lengnick-Hall, M.L., \& Jennings, K.R. (1988). Employee Participation: Diverse Forms and Different Outcomes. Academy of Management Review, 13: 8-22

Fiol, C.M. (1991). Managing Culture as a Competitive Resource: An Identity-Based View of Sustainable Competitive Advantage. Journal of Management, 17(1): 191-211

Frumkin, P. (2002). On Being Nonprofit: A Conceptual And Policy Primer. Cambridge, Ma.: Harvard University Press

Jackson, S.E., Schuler, R.S. and Rivero, J.C. (1989). Organizational Characteristics as Predictors of Personnel Practices. Personnel Psychology, 42: 727-786

Jeavons, T.H. (1992). When the Management Is the Message: Relating Values to Management Practice In Nonprofit Organizations. Nonprofit Management and Leadership, 2(4): 403-417

Jones, E.E., G.C. Wood, and G.A. Quattrone. (1981). Perceived Variability of Personal Characteristics in In-Groups and Out-Groups: The Role of Knowledge and Evaluation. Personality and Social Psychology Bulletin 7: 523-528

Karl, K.A., Sutton, C.L. (1998). Job Values in Today's Workforce: A Comparison of Public and Private Sector Employees. Public Personnel Management, 27(4): 515-527

Kim, S. (2002). Participative Management and Job Satisfaction: Lessons for Management Leadership. Public Administration Review, 62(2): 231-241

Kotter, J.P., and J.L. Heskett. 1992. Corporate Culture and Performance. New York: Free Press

Lawler, E.E., Mohrman, S.A. \& Ledford, G.E. (1992). Employee Involvement and Total Quality Management. San Francisco: Josey Bass

Leana, C.R., Ahlbrandt, R.S., \& Murrell, A.J. (1992). The Effects of Employee Involvement Programs on Unionized Workers' Attitudes, Perceptions, and Preferences in Decision Making. Academy of Management Journal, 35(4): 861-873

Locke, E.A. (1976). The Nature and Causes of Job Satisfaction. In M.D. Dunnette (Ed.), Handbook of Industrial/Organizational Psychology. Chicago: Rand McNally

London, M. \& Howat,G. (1978). The Relationship between Employee Commitment and Conflict Resolution Behavior. Journal of Vocational Behavior, 13: 1-14

Mason, D.E. (1996). Leading and Managing the Expressive Dimension: Harnessing the Hidden Power Source of the Nonprofit Sector. San Francisco, Ca.: Jossey-Bass

McKelvey, B. \& Kilmann, R.H. (1975). Organization Design: A Participative Multivariate Approach. Administrative Science Quarterly, 20(March): 24-36 
Morgan, G. (1986). Images of Organization. Newbury Park: Sage

O'Toole, J. (1993). The Executive's Compass: Business and the Good Society. New York: Oxford

Pierce, J.L., Gardner, D.G., Cummings, L.L. and Dunham, R.B. (1989). Organization Based Self-

Esteem: Construct Definition, Measurement, and Validation. Academy of Management Journal, 32: $622-648$

Posner, B.Z., and W.H. Schmidt. (1992). Values and the American Manager: An Update Updated. California Management Review 34(3): 80-94

Posner, B.Z., and W.H. Schmidt. (1996). The Values of Business and Federal Government Executives: More Different Than Alike. Public Personnel Management, 25(3): 277-298

Rokeach, M. (1973). The Nature of Human Values. N.Y.: Free Press

Rokeach, M. , P.W. Smith, and R.I. Evans. (1960). Two Kinds of Prejudice or One? In The Open and Closed Mind. Ed. M. Research. New York: Basic Books

Rousseau, D. (1990). Normative Beliefs in Fund-Raising Organizations. Group and Organization Studies, 15(4): 448-460

Schein, E.H. (1992). Organizational Culture and Leadership. San Francisco: Josey-Bass

Schuler, R.S. (1989). Strategic Human Resources Management and Industrial Relations. Human Relations, 42(2): 157-184

Schuler, R.S. \& Jackson, S.E. (1987). Organizational Strategy and Organization Level as Determinants of Human Resource Management Practices. Human Resource Planning, 10(3): 125141

Seashore, S.E., Lawler, E.E., Mirvis, P., Cammann, C. (eds.) (1982). Observing and Measuring Organizational Change: A Guide to Field Practice. N.Y.: Wiley

Snell, S.A. (1992). Control Theory in Strategic Human Resource Management: The Mediating Effect of Administrative Information. Academy of Management Journal, 35(2): 292-327

Tesluk, P.E., Vance , R.J. and Mathieu, J.E. (1999). Examining Employee Involvement in the Context of Participative Work Environments. Group and Organization Management, 24(3): 271-299

Vroom, V.H. (1960). Some Personality Determinants of the Effects of Participation. Englewood Cliffs: Prentice Hall

Wagner, J.A. III, Leana, C.R., Locke, E.A., Schweiger, D.M. (1997). Cognitive and Motivational Frameworks in U.S. Research on Participation: A Meta-Analysis of Primary Effects. Journal of Organizational Behavior, 18(7): 49-66 
Wagner, J.A. III (1994). Participation's Effect on Performance and Satisfaction: A Reconsideration of Research Evidence. Academy of Management Review, 19: 312-330

Wiener, Y. (1982). Commitment in Organizations: A Normative View. Academy of Management Review, 7: 418-428

Wiener, Y. (1988). Forms of Value Systems: A Focus on Organizational Effectiveness and Cultural Change and Maintenance. Academy of Management Review, 13: 534-545

Yeung, A.K.O., Brockbank, J.W. \& Ulrich, D.O. (1991). Organizational and Culture Human Resource Practices: An Empirical Assessment. Organizational Change and Development, Volume 5, JAI Press 